San Jose State University

From the SelectedWorks of Cassandra Paul

February, 2018

\title{
Using the Real-time Instructor Observing Tool (RIOT) for Reflection on Teaching Practice
}

Cassandra Paul, San Jose State University

Emily West, University of Pennsylvania 
As physics educators, we are constantly looking for ways to improve our practice. There are many different kinds of professional development opportunities that have been shown to help us with this endeavor. We can seek assistance from professionals, like mentor teachers or centers for faculty development, we can attend workshops to learn new curricula or pedagogical skills, and we can engage in learning communities to develop shared visions and become more reflective educators. ${ }^{1}$ However, when these activities end, what can we do on our own to continue to improve? How can we track our improvement? And perhaps even most importantly, what can we do when these resources aren't available to us? While publications like The Physics Teacher offer excellent pedagogical practices we can try out in the classroom, how do we get feedback on what we decide to implement?

One way to continue to improve our practice is to to develop habits of Scholarly Teaching, a practice of gathering data from one's own class and analyzing it in the context of a question about teaching and learning, with the intention of improving teaching and learning outcomes. ${ }^{2}$ In this paper we describe a tool that gives an instructor access to data that describe how s/he spends time in the classroom. The Real-time Instructor Observing Tool (RIOT) is a free web application that allows the real-time classification of an instructor's actions during a classroom observation. Immediately following an observation, the RIOT auto-generates charts and graphs that give instructors timely feedback on their teaching. ${ }^{3}$ Because RIOT offers objective data for easy self-reflection, it can be a powerful resource for professional development and reflective practice. While the RIOT can and has been used to collect data for research purposes, ${ }^{4}$ the RIOT can also be used for informal instructor professional development outside of a research setting. In this paper we describe how university and high school science instructors can use the RIOT in pairs to collect information about their classroom practices in order to inform and foster reflection on their teaching.

\section{Overview of the RIOT}

The RIOT web application consists of icons that a classroom observer can press to indicate that they are seeing the instructor engaging in basic interactions. The types of interactions are meant to be low inference, such that no particular knowledge-base is required to decipher them. There are four main types of interactions: "Talking at Students," "Talking with Students," "Observing Students," and "Not Interacting." Each of these main categories has subcategories. For example, "Talking at Students" is broken up into explaining content and clarifying instructions. An abbreviated description of the RIOT categories is provided in table 1 and additional detail is provided in the RIOT FAQs within the web app. ${ }^{3}$ At any given time, an instructor can engage in these types of interactions with an "individual," a "small group," or the "whole class." 
Talking at Students

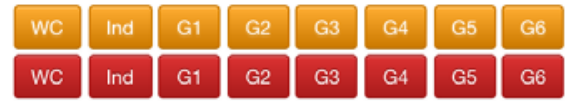

Shared Student/TA dialogue

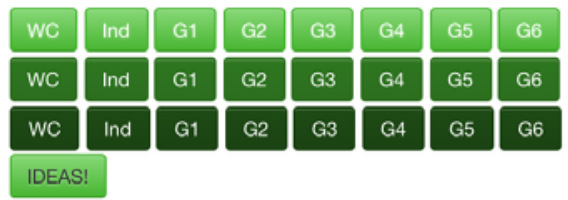

Observing Students
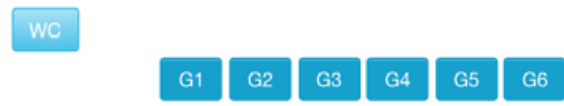

\section{Clarifying instructions \\ Explaining content}

Listening to question

Closed dialogue

Open ended dialogue

Passive: scanning class

Active: listening to one group

Student Presentation

Students Talking Serially
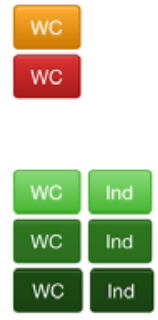

Not Interacting with Students

\begin{tabular}{l|l|lll}
\hline Administrative/Grading & Class Prep/Reading TA Notes & Chatting & Working on Apparatus/Material & Out of Room \\
\hline
\end{tabular}

Your Comments:

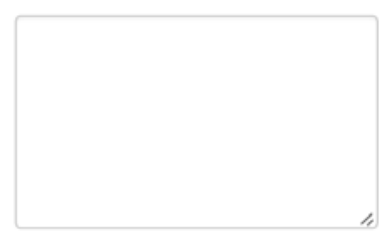

Submit Comment

Figure 1: Screenshot of the RIOT web interface.

When the classroom observer sees one of these interactions beginning to happen, they press the corresponding icon and the program timestamps the beginning of the interaction. When the interaction changes, the observer presses a new icon, and then the program timestamps the end of the first interaction and the beginning of the new one. In this way, the program collects information on what is happening during every moment of the class. Once a classroom observation is completed, the RIOT application auto-generates charts that allow for immediate analysis of classroom events. We have provided sample charts generated by the RIOT from two different classrooms in figures $2 \& 3$. The color indicates the type of interaction that is taking place at a given time, and the vertical position indicates with whom the instructor is interacting. The top row is for interactions during whole class discussion time. All other rows indicate that the students are expected to be working in groups. The second row is for times the instructor interacts with the whole class, even though it is small group (SG) time (for example: passively observing the whole class by scanning the room). The 3rd row is any interaction taking place during small group time that is dedicated to a group or individual, and those particular groups are also represented separately in the lower rows. 


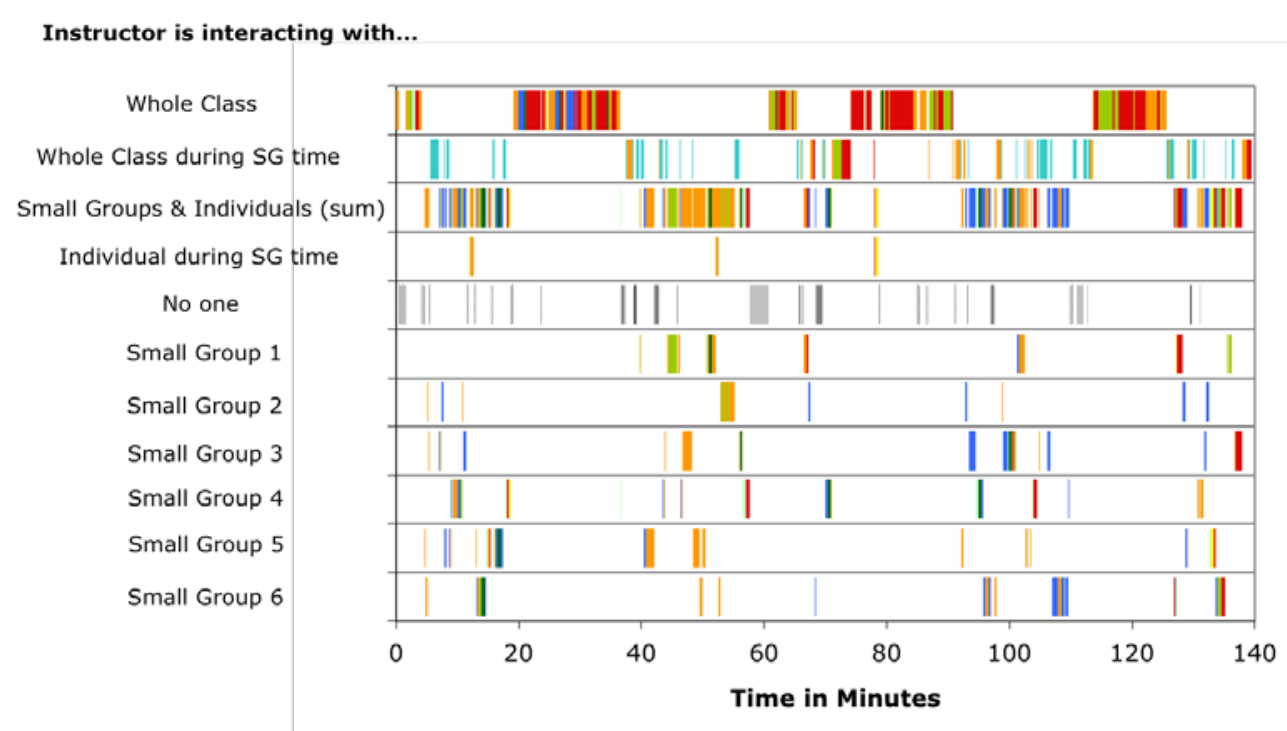

Figure 2: Timeline output from the RIOT for the class that Bruce teaches. (As collected by the vignette character Linda.)

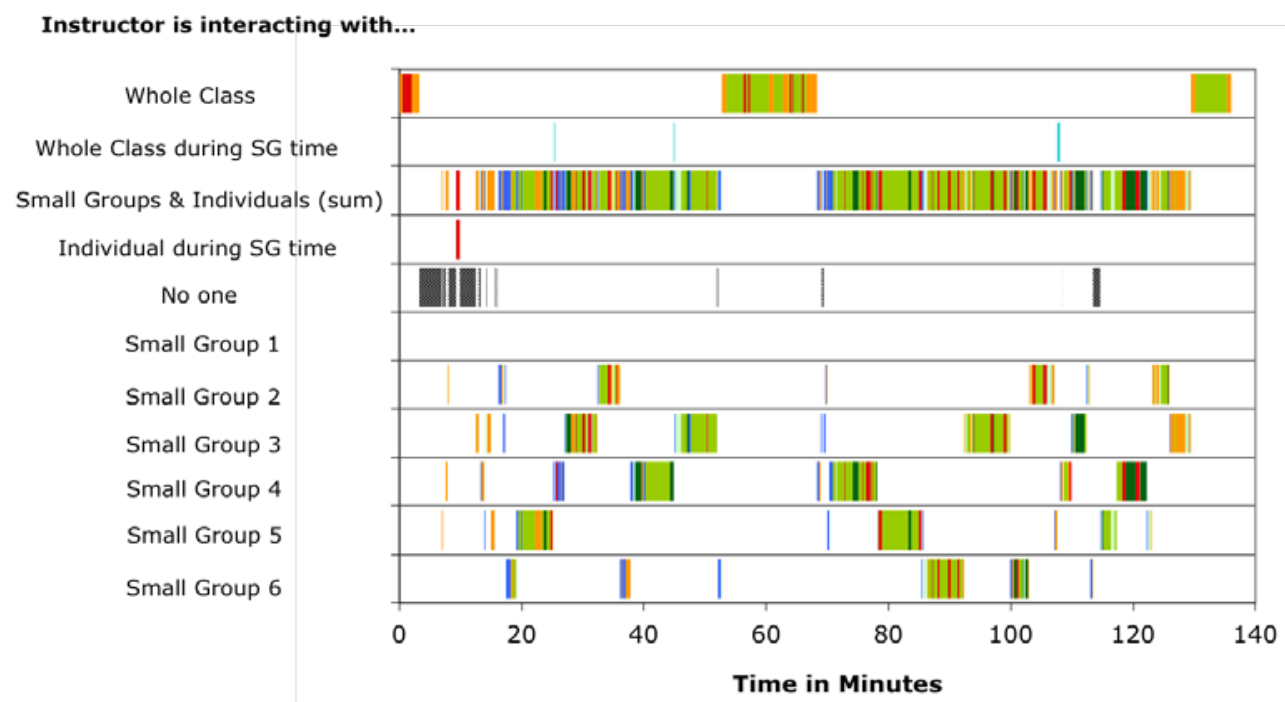

Figure 3: Timeline output from the RIOT for the class that Linda teaches. (As collected by the vignette character Bruce.) 
Clarifying

Instructions

Explaining

Content

Listening

Closed Dialogue

Open Dialogue

Shared Ideas

Passive

Observing

- Active Observing \&

Students Presenting

Students Talking Serially

Not Interacting (various)

Figure 4: Color-coded legend of the RIOT categories of interactions included in figures $2 \& 3$.

\begin{tabular}{|c|c|c|}
\hline $\begin{array}{c}\text { Type of } \\
\text { Interaction }\end{array}$ & Category of Interaction & Description (Instructor is...) \\
\hline \multirow[t]{2}{*}{$\begin{array}{l}\text { Talking } \\
\text { At Students }\end{array}$} & Clarifying Instructions & $\begin{array}{l}\text { Clarifying the instructions, reading from the activity sheet, covering } \\
\text { logistical issues, transitioning, .... }\end{array}$ \\
\hline & Explaining Content & Explaining physics concepts, answers, or processes to student(s). \\
\hline \multirow{4}{*}{$\begin{array}{l}\text { Dialoguing with } \\
\text { Students }\end{array}$} & Listening to Question & Listening to a student's question. \\
\hline & Engaging in Closed Dialogue & $\begin{array}{l}\text { Asking a series of short questions meant to lead the student to a correct } \\
\text { answer. Student contribution is one to several words at a time. }\end{array}$ \\
\hline & Engaging in Open Dialogue & $\begin{array}{l}\text { Students are contributing complete sentences, though not actively } \\
\text { "making sense." }\end{array}$ \\
\hline & Ideas being shared & $\begin{array}{l}\text { Participating in student-led conversation. Student contribution is com- } \\
\text { plete sentences with concepts being challenged and worked on. }\end{array}$ \\
\hline \multirow{4}{*}{ Observing Students } & Passive Observing & $\begin{array}{l}\text { Scanning room and assessing student progress from afar or browsing } \\
\text { whiteboard work of groups for less than ten seconds at a time. }\end{array}$ \\
\hline & Active Observing & Actively listening to small groups or individuals. \\
\hline & Students Presenting & Listening to students presenting their work to the class. \\
\hline & Students Talking Serially & $\begin{array}{l}\text { Listening to students talking serially, asking each other questions and } \\
\text { building on each others' ideas. }\end{array}$ \\
\hline \multirow{5}{*}{$\begin{array}{l}\text { Not } \\
\text { Interacting }\end{array}$} & $\begin{array}{l}\text { Administrative and/or } \\
\text { Grading }\end{array}$ & $\begin{array}{l}\text { Grading student homework, or discussing quizzes or other course } \\
\text { policies. }\end{array}$ \\
\hline & $\begin{array}{l}\text { Class Preparation or } \\
\text { Reading TA Notes }\end{array}$ & Reading notes, or writing something on the board. \\
\hline & Chatting & $\begin{array}{l}\text { Chatting socially with students. This is not an interaction concerning } \\
\text { physics. }\end{array}$ \\
\hline & $\begin{array}{l}\text { Working on Apparatus } \\
\text { and/or Material }\end{array}$ & $\begin{array}{l}\text { Helping students with experimental apparatus or computers. Any pos- } \\
\text { sible discussion is devoid of any physics content. }\end{array}$ \\
\hline & Out of room & Left the room. \\
\hline
\end{tabular}

Table 1: Description of the RIOT categories. Table adapted from West et al. 2013.

As it is our intent to show how STEM instructors can use the RIOT to reflect on their teaching practice, we have created a vignette that shows how two fictional instructors might make sense of their RIOT data. We have set up this vignette to take place in the context of two Collaborative Learning through Active Sense-making in Physics (CLASP) courses as this is the course the authors are both most familiar with, but it should be noted that the RIOT can be used in any course context.

\section{Vignette}


Overview: Two instructors, Linda and Bruce, are interested in improving their teaching. Each uses the CLASP curriculum, an introductory physics curriculum which utilizes both small group work and whole class discussions to foster student sense-making. Linda has been using the CLASP curriculum for years, and is comfortable in this interactive environment. Bruce has just adopted the CLASP curriculum and knows his previous years of experience with traditional lecture are influencing his adaptation. Both Linda and Bruce are looking for ways to improve their teaching practice. Linda doesn't have any specific goals, but Bruce is particularly interested in improving his interactions with his students during small group time. Pre-Observations: Linda and Bruce meet for an hour, logging into the RIOT and familiarizing themselves with the categories and data collection interface. They decide to observe the first half-hour of another instructor's classroom and meet afterwards to debrief. During the debrief, they realize that they mostly classified the instructor's interactions similarly, but in some cases Linda's observations showed orange where Bruce's showed red. They realize that this means that they have different interpretations about what clarifying and explaining categories mean so they have a five-minute conversation to solidify their mutual understanding of clarify vs. explain and settle on a mutual definition.

Observations: The next day Linda observes Bruce. Linda enters Bruce's classroom early and finds a spot out of the way to sit and observe the classroom. She then launches the RIOT application. She finds that from her vantage point she can easily hear the interactions between Bruce and his students so doesn't need to move around very much. The following day Bruce observes Linda. Bruce finds that in order to hear Linda he needs to move around the room because her class is active and noisy and it's difficult to hear Linda's conversations with her students. Later that afternoon, Bruce and Linda meet to debrief. Their data are shown in figures 2 and 3 respectively.

First Impression Reflection: Linda and Bruce display both of their RIOT data outputs and each take a minute summarizing their first impressions. Linda is immediately pleased to see large swaths of green representing open dialogue and closed dialogue with students in both the small group and whole class discussion rows. She tells Bruce that she has been working to decrease the amount of time she spends talking at students, and increase the amount of discussion that happens in class, and that these data are corroborating her efforts. Bruce notices that he spends roughly the same amount of time in whole class discussion as he does in small group time and is happy to see this change from his previous lecture-based teaching practice. The two decide to first reflect on Bruce's data and then to switch to Linda's pulling in relevant information from both observations as they go.

Bruce's Reflection: Bruce notices that he has more red (explaining) than Linda in the whole class discussion and more orange (clarifying) in the group work parts of the class. Bruce is satisfied that his RIOT data matches his teaching philosophy for whole class discussions, but has some ideas about small group time. Bruce explains to Linda that by implementing CLASP group work, his plan had been to explain for short periods of time during whole class discussion and to dialog with the students during the small group time. Therefore, he was surprised to see so little green in the small group row. Linda recalls that this was hard for her at first too, and suggests that if students ask him, "Is this right?" or lament, "We are stuck!" instead of launching into an explanation, he might instead say, "Can you walk me through your reasoning? What assumptions have you made? Tell me about what ideas came to your head when you first started this problem." Bruce jots the questions down, and plans to try them out next class.

Another thing Bruce notices is frequently occurring minutes of non-interacting time. When Bruce asks Linda about this, she indicates that he appeared to be looking at his notes during 
this time. Bruce is surprised by this because he did enough preparing before class that he should not have needed to spend so much time looking at his notes. On reflection, he realizes that he is probably looking at his notes because he doesn't feel immediately needed by his students and is looking for something else to do. Since he has a goal to increase time spent interacting with students, he decides that when he finds himself unnecessarily looking down at his notes he will instead make an effort to passively and actively observe his students, so he is better able to engage them in dialogue when needed. Linda suggests that this is a good idea and might actually make him appear more available during class.

\section{Linda's reflection:}

Linda begins by analyzing her RIOT data for whole class discussions. She is satisfied with the amount of closed dialogue, but notices a complete absence of student presentations during whole class time. She found that Bruce's student presentations added a lot to the class and therefore decides to start having groups present their work in her next class.

In considering her small group data, Linda notices some changes from the beginning to end of the class time. Early in the class, Linda begins interactions by actively observing each group, which she does to get a better understanding of where they are before she helps them. However, later in the class (when she typically feels more rushed) she drops the active observing, and instead just walks from group to group in a somewhat predictable pattern. She is typically rushing from group to group, and Bruce indicates that she sometimes misses when a particular group is completely stuck and needs help. Bruce points out that surveying the class with passive observation enables him to keep track of the whole classroom, identify which groups are stuck, and offer assistance in an efficient way. They notice that Bruce has much more light blue (passive observation) than Linda. Linda and Bruce consider the different purposes of active and passive observing in each of their classes, and have a productive discussion on the instructional benefits of taking time to assess where students are. Linda makes the decision to incorporate more passive observation throughout her class, and also to make a conscious effort to try to continue to make time for active observing in the later portions of the class period.

Summary: Linda and Bruce finish their reflection by reiterating what they have learned, and also writing down the action items items they discussed so that they can remember them for next class. In general, Linda is satisfied that her RIOT data matches her teaching philosophy's emphasis on dialogue. She uses the data to improve classroom management during small group time by spending more time passively observing and also decides incorporate a new strategy in whole class discussions, student presentations. Bruce feels like he has a better idea of what is happening in his class, and through his discussions with Linda, has developed some ideas on how to be more interactive with his students during small group time. After consulting the RIOT Step-by-Step plan outlined in this article, they each decide to select one action item each to focus on for their next class meeting, saving the other action items for future class meetings. Linda chooses to incorporate more passive observing into her practice, and Bruce decides to concentrate on dialoguing with students by using the question prompts Linda suggested.

\section{End Vignette}

The vignette we share is neither exhaustive nor exemplary, but merely an example of conversations that the RIOT data allows instructors to have. The power of the RIOT is that 
by providing information about what happened in class, it gives instructors the opportunity to make progress in ways that they feel appropriate. For example, Bruce is not interested in pedagogically changing his whole class discussions from lecture to dialogue as Linda has. However, there are other ways that he can use the RIOT to improve his teaching practice and the data allow him to reflect on his teaching in a meaningful way, empowering him to make decisions on how he can be more effective.

Below we have provided a step-by-step plan for using the RIOT to improve teaching practice. We strongly suggest working in reflective pairs, but understand that in some cases it may be difficult or uncomfortable to find a dedicated partner. If you are interested in a more detailed plan, or would like instructions for solo reflection, please see online supplementary materials for extensive instructions.

The RIOT step-by-step plan for reflection

\section{Step 1 ) Find an observing partner}

\section{Step 2 ) Familiarize each other with the RIOT interface and categories of interaction}

Step 3 ) (Optional) Observe someone else's class together, each take practice data, talk about what you see and what the RIOT categories mean in this context. ${ }^{5}$

\section{Step 4) Observe each other}

\section{Step 5) Examine and discuss results}

Some questions you might use to start reflective discussion are listed here:

- Is your RIOT data what you expected?

- Are you interacting with your students as much as you thought you might? What is the breakdown of time spent talking at, talking with, observing, and not interacting with students?

- How long do you spend lecturing over a whole class period? What is the longest amount of time that you lecture in a row without changing your interaction mode? Does this match your teaching philosophy?

- Are you spending any time listening to and/or observing your students? What do you gain or miss by participating in or abstaining from these interactions?

- Are any individuals or groups receiving more/less of your time than expected? How does this impact those students and the other students in your class?

- Are the patterns of interactions you have with students the same types of patterns that you would like to have with an instructor if you were a student?

- How do you typically respond to student questions?

- Do you proceed through the room in a set pattern (e.g. group 1, group 2, group 3, etc.) or more randomly? What do you gain or lose from your method?

- Tell your partner about the strengths you saw in their classroom, and/or see in their RIOT data.

- What types of interactions happened in your partner's class that did not happen in yours? Ask your partner why they chose to incorporate this type of interaction, and what affordances and/or drawbacks there are to including it.

- What things in your data do you like seeing?

- What would you like to change? 
- What are some examples of actions you can take in the classroom to align your RIOT data with your teaching philosophy?

- What are some things you can do outside the classroom to prepare yourself to implement these changes?

Step 6) Decide what (if anything) you'd like to change, make plans to incorporate the changes

\section{Other instructional settings}

The data presented in the Linda/Bruce vignette is from instructors teaching CLASP, a reformed physics class with curriculum emphasizing small group discussion and instructor support to foster instructor/student dialog. Interactive classes that use more lecture elements will have RIOT outputs that look different from these. Furthermore, while the RIOT in theory could be used to make claims about one classroom exemplifying more interactivity than another, it's important to note that research has not yet shown that there is an optimal amount of interactivity to strive for. Therefore, we emphasize that use of the RIOT in this professional development context should be focused on improving instructors' understanding of what is happening in their classrooms, making sure classroom actions are aligned with the instructor's learning/teaching goals, and keeping track of intended changes to teaching practice. For these reasons, the RIOT can also be particularly useful when training new Teaching Assistants.

\section{Summary}

Using the RIOT can provide a valuable source of data and shared reflection on teaching practices, especially for those STEM instructors who often work in isolation. Most instructors have a teaching philosophy in mind that shapes the pedagogical landscape of their classes. However, it can be hard for an instructor to know if their students experience their class in a way that matches their vision. By having a colleague observe with the RIOT, an instructor can gain valuable data to further tailor instructional choices to match the instructor's teaching philosophy. Further, by operating in pairs, instructors can benefit from seeing other teaching methods and from engaging in interactive activities with a fellow STEM instructor. RIOT could also be used to complement co-teaching observations, ${ }^{6}$ as a part of new teacher and teaching assistant training, or even as a part of a teaching portfolio required by some institutions for retention and promotion. To access the RIOT, visit www.sjsuriot.appspot.com. ${ }^{3}$ You will need a gmail account to use it. If you are looking for resources and support for more research-based practice in your classroom, we recommend the sources we cite, and also browsing the physport.org, ${ }^{7}$ a database for research-based interactive instructional techniques.

\footnotetext{
${ }^{1}$ M. Borrego \& C. Henderson "Increasing the Use of Evidence-Based Teaching in STEM Higher Education: A Comparison of Eight Change Strategies," Journal of Engineering Education, 103(2), 220-252. (2014)
}

2 M. K. Potter \& E. D. H. Kustra "The Relationship between Scholarly Teaching and SoTL: Models, Distinctions, and Clarifications Recommended Citation The Relationship between Scholarly Teaching and SoTL: Models, Distinctions, and 
Clarifications," International Journal for the Scholarship of Teaching and Learning, 5(1) (2011)

${ }^{3}$ C. A. Paul \& A. Reid "SJSU Real-time Instructor Observing Tool (RIOT)" [Website application software]. Retrieved from http://sjsuriot.appspot.com/(2013)

${ }^{4}$ E. A. West, C. A. Paul, D. Webb, W. H. Potter "Variation of Instructor Student Interactions in an Introductory Interactive Physics Course," Phys. Rev. ST Phys. Educ. Res. 9, 010109 (March 2013)

${ }^{5}$ While in a research setting, it would be problematic if two individuals had different interpretations of the observation, teacher feedback indicates that this matters less in reflective pairs because participants still get a good sense of the overall class structure and atmosphere, and they are able to successfully communicate the ideas behind their classifications to their partners.

${ }^{6}$ C. Henderson, A. Beach, M. Famiano, "Promoting Instructional Change via CoTeaching," American Journal of Physics 77 (3), 274-283 (2009)

${ }^{7}$ S. B. McKagan et al. "PhysPort: Supporting physics teachers with research-based resources," [Website] Retrieved from https://www.physport.org/ (2011) 